\title{
NUMERICAL INVESTIGATION OF THE EFFECTS OF GEOMETRICAL PARAMETERS ON THE VORTEX SEPARATION PHENOMENON INSIDE A RANQUE-HILSCH VORTEX TUBE USED AS AN AIR SEPARATOR IN A HELICOPTER'S ENGINE
}

\author{
Adib BAZGIR, Nader NABHANI ${ }^{*}$ \\ Petroleum University of Technology, Ahwaz, Iran \\ Received 02 May 2017; accepted 21 February 2018
}

\begin{abstract}
Air separators are fitted to helicopter engine intakes to remove potentially harmful dust from the influent air. Their use is necessary in desert environments to eliminate the risk of rapid engine wear and subsequent power deterioration. However, their employment is concomitant with an inherent loss in inlet pressure and, in some cases, auxiliary power. There are three main technologies: vortex tubes, barrier filters, and integrated inlet particle separators. In this work, a vortex tube is investigated numerically. The study was conducted on the number and axial angle of inlet nozzles. Two and three-dimensional models are investigated at a steady state condition then the standard k- $\varepsilon$ turbulence model is utilised for determining the flow and temperature fields. The finite volume method base on a Computational Fluid Dynamic (CFD) model is verified through the comparison with experimental data and numerical results of a vortex tube, reported in literature sources. Increasing the number of inlet nozzles, increases the sensitivity of the temperature reduction and the highest possible temperature reduction can be obtained. A vortex tube with an axial angle inlet nozzle of yields better performance. The numerical simulation results indicated that the CFD model is capable of predicting the vortex separation phenomenon inside a Ranque-Hilsch vortex tube with different geometrical parameters.
\end{abstract}

Keywords: vortex separation phenomenon, air separator, Ranque-Hilsch vortex tube, inlet nozzle, cold and hot outlet, CFD.

\section{Introduction}

A vortex tube, also called a Ranque-Hilsch vortex tube (RHVT), is a simple device with no moving parts that converts a pressurized gas of a homogeneous temperature into two streams of different temperature, one warmer than the inlet and one cooler simultaneously. Vortex tubes are generally classified into two types based on the cold exit position: counter-flow vortex tubes and parallel-flow vortex tubes. In counter-flow vortex tubes, the cold fluid outlet is placed on the opposite end of the hot fluid outlet. In parallel tubes, the cold and hot fluid outlets are located at the same end. In this paper, a counter-flow geometry has been chosen. As shown in Figure 1, a vortex tube mainly consists of one or more inlet nozzles, a vortex chamber, a cold orifice and a control valve that is located at the hot end. A vortex tube refrigerator has many advantages over conventional commercial refrigeration devices such as: simplicity, durability, smallness or lightness of weight, low cost, no need of electricity or chemicals, adjustability of temperature, and being more environmentally friendly (Eiamsa-ard \& Promvonge, 2008b; Khodorkov, Poshernev, \& Zhidkov, 2003; Konzen, 1971; Lucca-Negro \& O’doherty, 2001; Pouraria \& Zangooee, 2012; Van Patten \& Gaudio, 1969; Williams, 1971; Bazgir, 2017a, 2017b; Bazgir, Heydari, 2018). Vortex tubes have been widely used in various applications, including heating and cooling (Bazgir, Nabhani, 2018), drying gasses (Pouraria \& Zangooee, 2012), gas liquefaction (Park \& Pouraria, 2014), separation of gas mixture (Riu, Kim, \& Choi, 2004), etc.

The Ranque-Hilsch vortex tube was first reported by Ranque (Eiamsa-ard \& Promvonge, 2008b) in 1933 and was later popularized by Hilsch (1947). Since then, many efforts have been made to investigate the temperature/energy separation in the RHVT. In experimental work, many investigations have been done to improve the efficiency of the RHVT. Saidi and Valipour (2003) in their experimental

${ }^{*}$ Corresponding author. E-mail: nabhani@put.ac.ir 


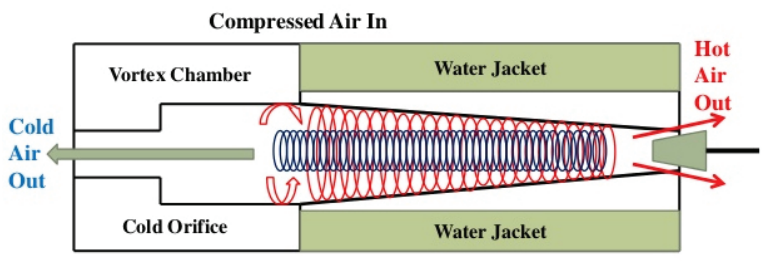

Figure 1. Flow structure in a counter-flow vortex tube

study examined the classification of the parameters affecting vortex tube operation. The thermo-physical parameters such as inlet gas pressure, type of gas and cold gas mass ratio, moisture of inlet gas and the geometrical parameters such as the diameter of the main tube and shape of entrance nozzle and hot control valve were designed and studied. Valipour and Niazi (2011) experimentally investigated the effect of the vortex tube curvature from $0^{\circ}$ to $150^{\circ}$ on its performance. They concluded that straight and $150^{\circ}$ curved vortex tubes have a higher performance as refrigerators than the other curvature angles. Xue, Arjomandi, and Kelso $(2012,2013 a, 2013 b)$ provides a detailed description of flow behaviour inside a vortex tube and addresses the mechanism of the generation of cold and hot streams in a vortex tube, which is confirmed by different experimental methodologies, including a visualization of flow structure in a water operated vortex tube and measurement of velocity profiles in both water and air operated vortex tubes. Chang, Li, Zhou, and Li (2011) performed experimental research with a hot divergent tube and found that the energy separation performance of a vortex tube can be improved by using a divergent hot vortex tube. However, only part of the flow parameters can be calculated by experiments, most of the detailed and important data are very difficult to obtain. These data, such as flow pattern and structure, are very important for understanding the energy separation phenomenon. Eiamsa-ard, Wongcharee, and Promvonge (2010) conducted an experimental study on the effect of cooling the hot-tube and found that energy performance can be higher than that of the vortex tubes without the cooling.

Due to the limitations of the experimental work, some efforts have been made to successfully utilize computational fluid dynamics (CFD) to find numerical simulations to explain the fundamental principle behind the energy separation within the vortex tube. Fröhlingsdorf and Unger (1999) studied fluid flow and energy separation in a vortex tube by using a CFX code along with the $\mathrm{k}-\varepsilon$ model. Aljuwayhel, Nellis, and Klein (2005) used a twodimensional axisymmetric CFD model to investigate the vortex tube energy separation mechanism and their results proved that their numerical model could predict the temperature separation successfully. Behera et al. (2005) presented a three-dimensional CFD model for the analysis of energy separation using the STAR-CD-Software with the RNG k- $\varepsilon$ turbulence model. Eiamsa-ard and Promvonge $(2007,2008 \mathrm{a})$ carried out a numerical simulation to examine the phenomena of the flow field and energy separation inside vortex tube flows. Skye, Nellis, and Klein (2006) conducted research similar to Aljuwayhel et al. (2005). Kazantseva, Piralishvili, and Fuzeeva (2005) simulated the swirling flow using CFX-TASK software. Farouk, T. and Farouk, B. (2007) used large eddy simulation to obtain the energy separation inside a vortex tube. They compared the predicated results with the published experimental results of Skye et al. (2006). Behera, Paul, Dinesh, and Jacob (2008) investigated the variation of fluid properties and flow parameters as the fluid particles progress in the flow field by tracking different particles exiting through the hot and cold end. Pouraria and Zangooee (2012) studied the performance of a vortex tube refrigerator with a divergent hot-tube based on a two dimensional axis-symmetrical Bovand, Valipour, Dincer, and Tamayol (2014) studied the performance of a vortex tube refrigerator with a curved hot tube based on a three dimensional and utilized the RNG k- $\varepsilon$ turbulence model for determining the flow and temperature fields. Liu, X. and Liu, Z. (2014) presented a three-dimensional model with the consideration of fluid compressibility and strong swirling characteristics. They also compared the existing turbulence models and found that RNG k- $\varepsilon$ turbulence and standard $k-\varepsilon$ models are more suitable for the numerical simulation of the vortex tube.

Past studies show that vortex tubes with different thermo-physical parameters such as inlet gas pressure, type of gas and cold gas mass ratio, moisture of inlet gas, diameter of the main tube, shape of entrance nozzle and hot control valve have been designed and studied experimentally. In this paper, the numerical study focuses on disclosing the influence of parameters like the number and axial angle of inlet nozzles on the operational characteristics of a vortex tube refrigerator. Hence, the numerical simulation is carried out to simulate the internal flow profiles. The simulation is verified through a comparison with experimental results reported in literature sources. For comparison, the data for counter-flow vortex tubes with different geometrical parameters has been obtained under similar conditions.

\section{Problem description}

\subsection{Geometrical model description}

Compressed air is conducted inside a vortex tube through the inlet nozzles which play an important role for creating a swirling flow. After the air enters the vortex tube, the flow starts to swirl from inlet nozzles to the hot and cold outlet of the vortex tube. As described above, a vortex tube consists of the horizontal tube, some inlet nozzles, a hot outlet which is located on the wall at the end of the horizontal tube, and a cold outlet which is an axial outlet opposite of the hot outlet. Creating geometry and meshing is necessary for simulating this project. Most of the time, for simplifying the process of computing equations, a twodimensional axisymmetric swirl model is used, however for a greater explanation, a three-dimensional model of 
a vortex tube is investigated in this study too. Both the modelling and meshing of the geometry are performed by software Gambit 2.4.6. A comparison between a twodimensional axisymmetric swirl and a three-dimensional model of a vortex tube can provide accurate verification for choosing the axisymmetric swirl assumption for a twodimensional model.

\subsubsection{Two dimensional axisymmetric swirl model}

The Skye et al. (2006) model is chosen for this simulation, as shown in Figure 2. When flow distributes around an operating axis symmetrically, the axisymmetric swirl model will be an accepted assumption for the simulation. In this case, the parameter $\frac{\partial}{\partial \theta}$ of should be deleted from all cylindrical equations, then flow analyses in the r-x coordinate.

\subsubsection{Three-dimensional model}

The most important issue that raises doubt in applying a two-dimensional axisymmetric swirl as the model is the location of inlet nozzles; therefore, for investigating the effect of inlet nozzles on the performance of a vortex tube, a three-dimensional model with a different number of inlet nozzles was chosen. A six-inlet-nozzle vortex tube with its cold and hot outlets is shown in Figure 3. The hot control valve is located at the end of the vortex tube and controls the cold mass flow rate by changing the pressure of the hot outlet. For simplifying the model and the process of simulation, the hot outlet is assumed to be a simple radial outlet.

\subsection{Performance parameters}

\section{- Cold mass fraction}

The most important operating parameter is the cold mass fraction. This parameter can be controlled by the hot control valve, which is located at the end of the vortex tube.

- Cold temperature difference

Cold temperature difference is the difference between the temperature of the inlet and cold outlet.

$$
\begin{aligned}
& \lambda=\frac{\dot{\mathrm{m}}_{c}}{\dot{\mathrm{m}}_{\text {in }}} ; \\
& \Delta T_{c}=T_{\text {in }}-T_{c},
\end{aligned}
$$

where $T_{\text {in }}$ is the inlet temperature and $T_{c}$ is the cold outlet temperature.

\subsection{Governing equations}

The high swirling and compressible turbulent flow inside the vortex tube is analysed at two and three-dimensional, steady state conditions and the standard k- $\varepsilon$ turbulence model is applied. Bramo and Pourmahmoud showed that the standard k- $\varepsilon$ model can be chosen to analyse the effect of flow inside the vortex tube as a computational domain (Bramo \& Pourmahmoud, 2011). They also applied other different advanced turbulence models like the RNG (Renormalized group) $\mathrm{k}-\varepsilon$ models and Reynolds stress equations and, finally, understood that these models cannot lead the numerical analysis to a convergence simulation.

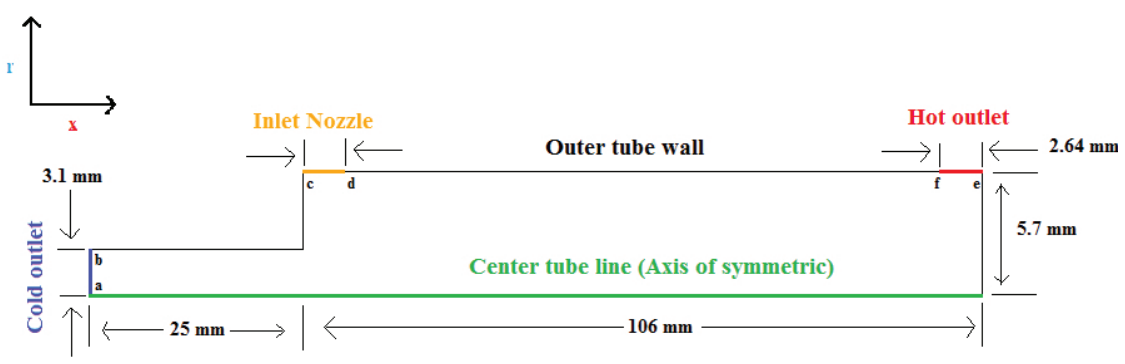

Figure 2. A schematic diagram of the two-dimensional axisymmetric model

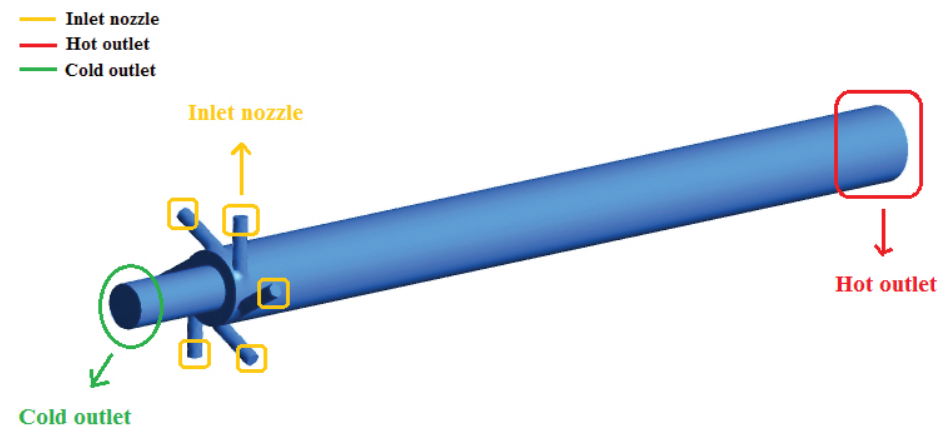

Figure 3. A three-dimensional geometry of a vortex tube with an inlet and outlets 
Consequently, the governing equations including conservation of mass, momentum, and energy are given below:

$$
\begin{gathered}
\frac{\partial}{\partial t}(\rho)+\frac{\partial}{\partial x_{j}}\left(\rho \tilde{u}_{j}\right)=0 ; \\
\frac{\partial}{\partial t}\left(\rho u_{i}\right)+\frac{\partial}{\partial x_{j}}\left(\rho \tilde{u}_{j} u_{i}-\tau_{i j}\right)=-\frac{\partial P}{\partial x_{i}} ; \\
\frac{\partial}{\partial x_{j}}\left[u_{i} \rho\left(h+\frac{1}{2} \tilde{u}_{j} \tilde{u}_{j}\right)\right]=\frac{\partial}{\partial x_{j}}\left[K_{e f f} \frac{\partial T}{\partial x_{j}}+u_{i}\left(\tau_{i j}\right)_{e f f}\right] ; \\
K_{\text {eff }}=\mathrm{K}+\frac{C_{p} \mu_{t}}{p r_{t}} .
\end{gathered}
$$

According to the ideal gas assumption for the working fluid, the compressibility effect must be calculated as follows:

$$
P=\rho R T .
$$

The turbulence kinetic energy $(\mathrm{k})$ and the rate of dissipation $(\varepsilon)$ are calculated from the following equations:

$$
\begin{aligned}
& \frac{\partial}{\partial t}(\rho k)+\frac{\partial}{\partial x_{i}}\left(\rho k u_{i}\right)= \\
& \frac{\partial}{\partial x_{j}}\left(\left(\mu+\frac{\mu_{t}}{\sigma_{k}}\right) \frac{\partial k}{\partial x_{j}}\right)+G_{k}+G_{b}-\rho \varepsilon-Y_{M} .
\end{aligned}
$$

In these equations, $G_{k}, G_{b}$, and $Y_{M}$. represent the generation of turbulence kinetic energy due to the mean velocity gradients, the generation of turbulence kinetic energy due to buoyancy, and the contribution of the fluctuating dilatation in compressible turbulence to the overall dissipation rate, respectively. $C_{1 \varepsilon}$ and $C_{2 \varepsilon}$ are constants. $\sigma_{k}$ and $\sigma_{\varepsilon}$ are the turbulent Prandtl numbers for $\mathrm{k}$ and $\varepsilon$ also. The turbulent (or eddy) viscosity, $\mu_{t}$, is imposed as follows:

$$
\frac{\partial f_{l, m}}{\partial \vec{a}}=\left\{x_{i}, x_{j} .\right.
$$

Here, $C_{\mu}$ is constant. The values of model constants $C_{1 \varepsilon}, C_{2 \varepsilon}, C_{\mu}, \sigma_{k}$ and $\sigma_{\varepsilon}$ are: $C_{1 \varepsilon}=1.44, C_{2 \varepsilon}=1.92$, $C_{\mu}=0.09, \sigma_{k}=1.0, \sigma_{\varepsilon}=1.3$. A finite volume method (FVM) with $2 \mathrm{D}$ and $3 \mathrm{D}$ structured meshes, which is one of the numerical methods to describe the complexity flow patterns inside the vortex tube, is applied to the given governing equations. It is considered that the compressibility of inlet air is a working fluid, where its thermal conductivity, specific heat and dynamic viscosity remain constant during this study procedure.

\subsection{Boundary condition}

\subsubsection{Inlet}

The pressure condition for the inlet nozzles of a vortex tube was chosen. The inlet of the vortex tube is specified by total pressure, total temperature and the direction of inlet flow. According to experimental data, the operating conditions are: almost constant, and inlet pressure and temperature are specified at $300 \mathrm{KPa}$ and $300 \mathrm{~K}$ respectively; the direction of flow has also been chosen normal to the boundary condition.

\subsubsection{Cold outlet}

The pressure condition was chosen for the cold outlet of the vortex tube and the static pressure is assumed to be constant at the cold outlet. According to the experimental data, the total pressure of the cold outlet is set at $103 \mathrm{KPa}$ in this numerical analysis. Computational fluid dynamic shows a back flow around the cold outlet at low cold-mass fractions. The temperature of back flow was set at $290 \mathrm{~K}$, which is equal to the temperature of the cold flow exit. The software can solve this simulation by trial and error by replacing the new computed value of temperature instead of the previous value many times until the solution converges.

\subsubsection{Hot outlet}

For the hot outlet, the pressure condition was chosen as a boundary condition exactly similar to the cold outlet; however, the hot outlet pressure is not constant. It varies in this study and causes different cold mass fractions.

\subsubsection{Wall}

A no-slip boundary condition was chosen for walls; therefore, all velocity components will be zero over the wall surface. The heat flux is zero through the walls and the walls are assumed to be adiabatic.

\subsection{Computational domain and mesh study}

All heat transfer, turbulence and related flow behaviour equations are used for compressible fluids. The solver method is the Finite volume method (FVM) based on computational fluid dynamics (CFD). The working fluid is air with ideal gas density and the Quick scheme is used for momentum, energy and turbulence equations to ignore the displacement and convective terms. Standard k- $\varepsilon$ turbulence model is used to characterize flow behaviour inside the vortex tube. The process of solver for a two-dimensional axisymmetric swirl and a three-dimensional model of vortex tube with six inlet nozzles is described step by step in Ansys Fluent 16.1. The process of solver with another number of inlet nozzles is exactly the same as for the vortex tube with six inlet nozzles. To solve continuity, momentum, energy and turbulence equations, the geometry should be meshed before in Gambit 2.4.6. By increasing the number of meshes, the time of solving the equations will increase. If the number of meshes decreases in critical sections, computational error increases too. Thus, the mesh dependency has been done and an optimized number of mesh also has been found. The size of mesh at the inlet, cold and hot outlets was chosen to be smaller than at the other places, which the average size of every mesh element varying from 0.5 to $5 \mathrm{~mm}$ there. The mesh of the two-dimensional axisymmetric swirl and the three-dimensional models are shown in Figure 4(a,b). 


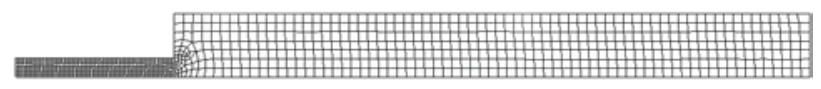

(a)

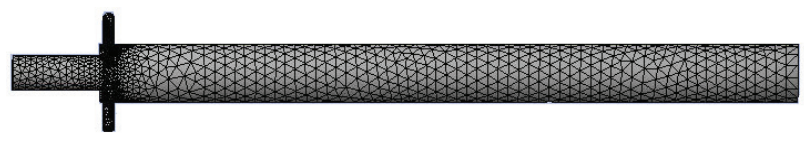

(b)

Figure 4 . The mesh cells of the (a) axisymmetric and (b) threedimensional model of the vortex tube

The mesh dependency diagram related to the cold and hot temperature difference was shown for the twodimensional axisymmetric swirl and the three-dimensional model versus a number of meshes and the volume of each mesh respectively. According to Figure 5, for the two-dimensional axisymmetric swirl model, the number of meshes increases from 3000 to 24000 with an increasing step of 3000 . As seen, there is no significant various in temperature for more than 15000 meshes. In Figure 6, the dependence of the three-dimensional mesh is shown: the volume of each element varies from $0.14 \mathrm{~mm}^{3}$ to $0.02 \mathrm{~mm}^{3}$ with a decreasing step of $0.02 \mathrm{~mm}^{3}$. Results show that there is no significant change in the temperature difference for the volume of each mesh less than $0.04 \mathrm{~mm}^{3}$.

\subsection{Process of problem solving}

\subsubsection{Solver}

In Table 1, the options which are chosen in the software are shown. Considering the compressibility of flow inside the vortex tube, the pressure and temperature variation causes the density difference. A density based solver was chosen in this numerical analysis. Both an explicit and an implicit solver are chosen for the two-dimensional axisymmetric swirl model; however, for the three-dimensional model, because of the mesh complexity and difficulty of convergence condition, only the explicit solver has been implemented. The axisymmetric swirl and 3D

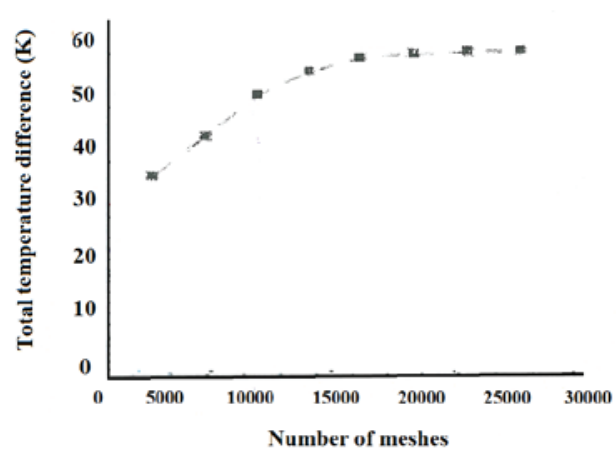

Figure 5. The variations of the total temperature difference $\left(\Delta \mathrm{T}=\mathrm{T}_{h}-\mathrm{T}_{c}\right)$ with a different number of meshes for the axisymmetric model

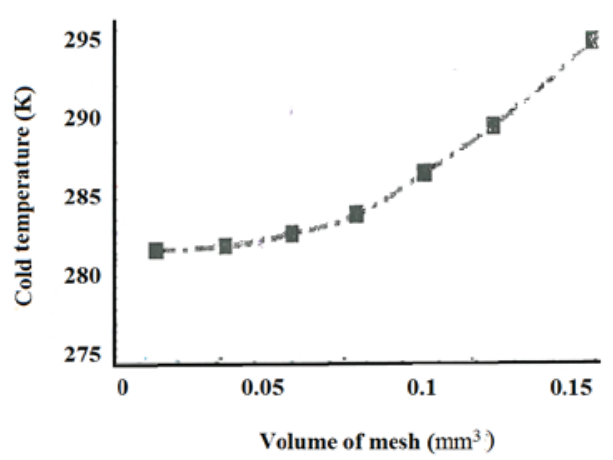

Figure 6. The variations of the cold temperature outlet $\left(\mathrm{T}_{c}\right)$ with the volume of each mesh $\left(\mathrm{mm}^{3}\right) \mathrm{r}$ the three-dimensional model

space are chosen for the two and three-dimensional model respectively. The simulation is done at a steady state time dependency for both models.

\subsubsection{Turbulence model}

From viscous models, a standard $\mathrm{k}-\boldsymbol{\bigotimes}$ turbulence model is chosen with a standard wall function condition, which is shown in Table 2.

Table 1. General details of the models in the software

\begin{tabular}{|l|l|l|l|l|}
\hline \multicolumn{1}{|c|}{ Model } & \multicolumn{1}{|c|}{ Solver } & \multicolumn{1}{c|}{ Space } & \multicolumn{1}{c|}{ Formulation } & \multicolumn{1}{c|}{ Time } \\
\hline Axisymmetric (2-D) & Density base & Axisymmetric swirl & Implicit- Explicit & Steady \\
\hline Three dimension & Density base & $(3-\mathrm{D})$ & Explicit & Steady \\
\hline
\end{tabular}

Table 2. Turbulence model features in the software

\begin{tabular}{|l|l|l|}
\hline \multicolumn{1}{|c|}{ Model } & \multicolumn{1}{|c|}{ Turbulence model } & \multicolumn{1}{c|}{ Wall flow condition } \\
\hline Axisymmetric (2-D) & Standard k- $\varepsilon$ & Standard wall function \\
\hline Three dimension & Standard k- $\varepsilon$ & Standard wall function \\
\hline
\end{tabular}


Table 3. Physical properties of the operating fluid

\begin{tabular}{|l|l|l|c|c|c|c|}
\hline \multicolumn{1}{|c|}{ Model } & Material & \multicolumn{1}{|c|}{ Density } & $\begin{array}{c}\text { Specific heat } \\
\text { capacity }\end{array}$ & \multicolumn{1}{|c|}{$\begin{array}{c}\text { Thermal } \\
\text { conductivity }\end{array}$} & $\begin{array}{c}\text { Dynamic } \\
\text { viscosity }\end{array}$ & Molecular weight \\
\hline Axisymmetric (2-D) & Air & Ideal gas & 1006.43 & 0.0242 & $1.789 \times 10^{-5}$ & 28.96 \\
\hline Three dimension & Air & Ideal gas & 1006.43 & 0.0242 & $1.789 \times 10^{-5}$ & 28.96 \\
\hline
\end{tabular}

\subsubsection{Physical properties of the operating fluid}

The physical properties of the operating fluid can be seen in Table 3. The density of the operating fluid determines it as an ideal gas and the temperature can vary in the range of 250 to $350 \mathrm{~K}$, while an average temperature of $300 \mathrm{~K}$ is chosen for the inlet fluid temperature.

\subsection{Validation}

For evaluating the research results, all data have been validated and compared with results in (Skye et al. 2006). The ratio of the hot and cold temperature difference versus cold mass fractions has been plotted and is shown in Figure 7. As illustrated, the results in different cold mass fractions have an acceptable validation and verification with experimental data and the numerical results of Skye et al. (2006).

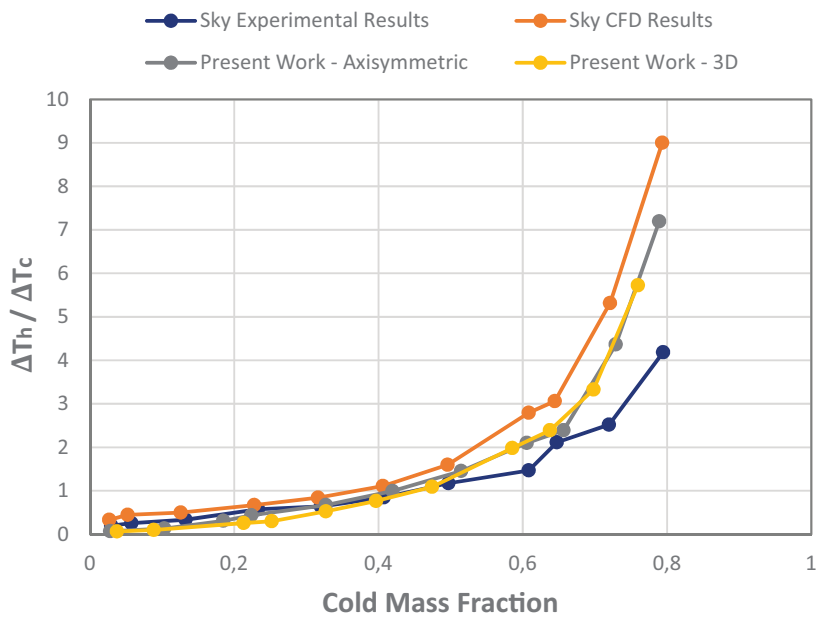

Figure 7. Ratio of hot $\left(\Delta T_{h}\right)$ and cold $\left(\Delta T_{c}\right)$ temperature difference versus the cold mass fraction $(\lambda)$

\section{Results and discussions}

\subsection{Number of inlet nozzles}

The effect of the number of inlet nozzles on the performance of the vortex tube is investigated. The temperature separation and velocity distribution of the vortex tube at $\mathrm{P}_{\text {in }}=300 \mathrm{KPa}$ are shown in Figure $8(\mathrm{a}, \mathrm{b})$ respectively. Two, four and six inlet nozzles are investigated for evaluating the performance of the vortex tube. The most important parameter causing the temperature separation phenomenon is the swirling flow inside the vortex tube, which is shown schematically in Figure $8(\mathrm{~b})$.
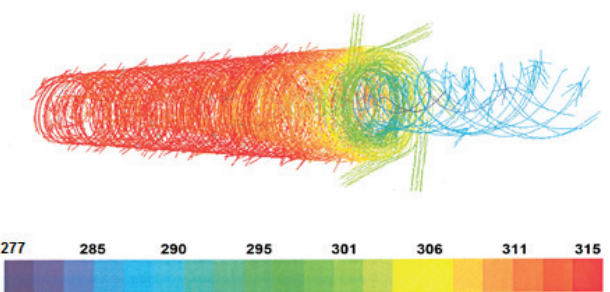

(a)

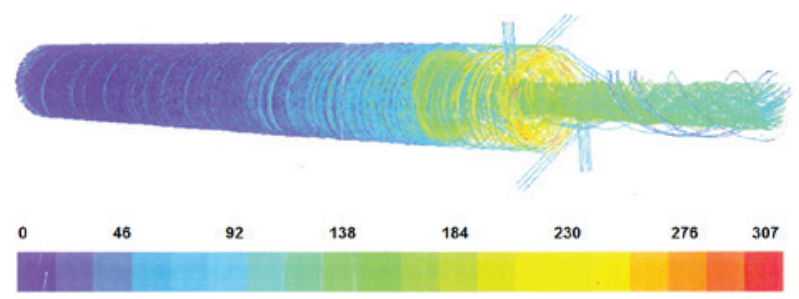

(b)

Figure 8. The distribution of (a) temperature and (b) velocity of the vortex tube at $\mathrm{P}_{\text {in }}=300 \mathrm{KPa}$

In this study, the number of inlet nozzles changes but the total inlet surface area will remain at a constant value of $8.2 \mathrm{~mm}^{2}$ in line with the Skye et al. (2006) model. Thus, when the vortex tube has six inlet nozzles, the surface area of each nozzle will be different when compared with those with four and two nozzles. The the diameter and the surface area of each inlet nozzle are indicated in Table 4.

Table 4. Information on the different inlet nozzles

\begin{tabular}{|l|c|c|}
\hline Number of nozzles & $\begin{array}{c}\text { Diameter of nozzle } \\
(\mathrm{mm})\end{array}$ & $\begin{array}{c}\text { Area of nozzle } \\
\left(\mathrm{mm}^{2}\right)\end{array}$ \\
\hline Two & 2.285 & 4.1 \\
\hline Four & 1.617 & 2.05 \\
\hline Six & 1.32 & 1.3667 \\
\hline
\end{tabular}

The temperature distribution for two, four and sixinlet nozzle vortex tubes is shown in Figure 9. Increasing the number of inlet nozzles can decrease the surface area of each of them, thus the velocity of the fluid will increase and swirling velocity will reach the maximum value in every region inside the vortex tube.

To analyse the effect of the number of inlet nozzles on the temperature separation phenomenon inside the vortex tube, the velocity distribution, especially the tangential velocity component, should be considered as a key parameter to study and characterize the flow behaviour inside the vortex tube. The velocity vectors for vortex tubes with two, four and six inlet nozzles are shown in Figure 10. 

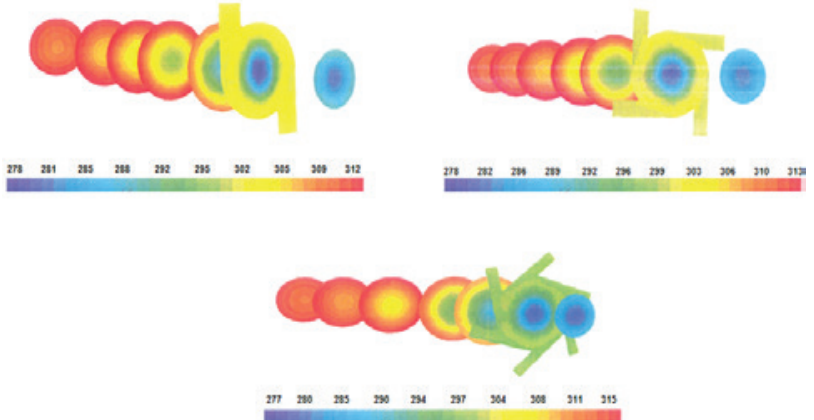

Figure 9. Temperature distribution for vortex tubes with two, four and six inlet nozzles

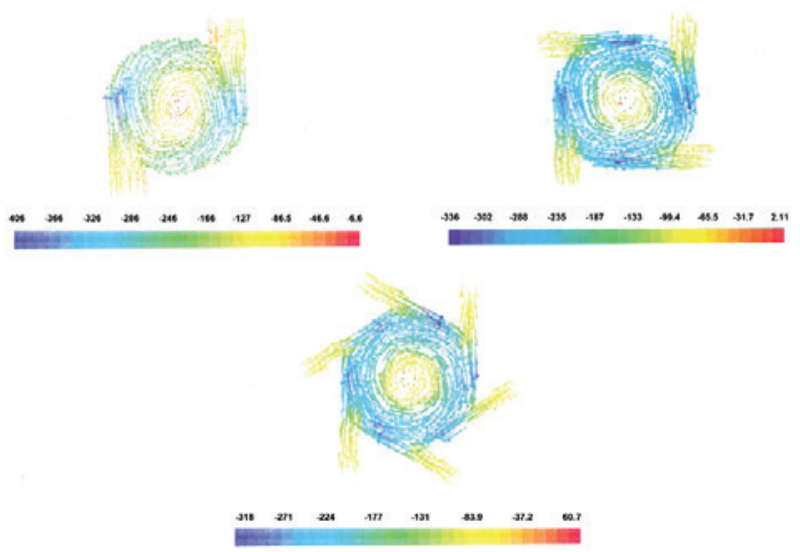

Figure 10. Velocity vectors for vortex tubes with two, four and six inlet nozzles

Generally, when the tangential velocity component increases, the pressure gradient will increase as well, which can lead to more temperature separation. For six inlet nozzles, the tangential velocity is the most predominant velocity component and is higher than the tangential velocity of vortex tubes with four and two inlet nozzles. One phenomenon reducing the performance of the vortex tube

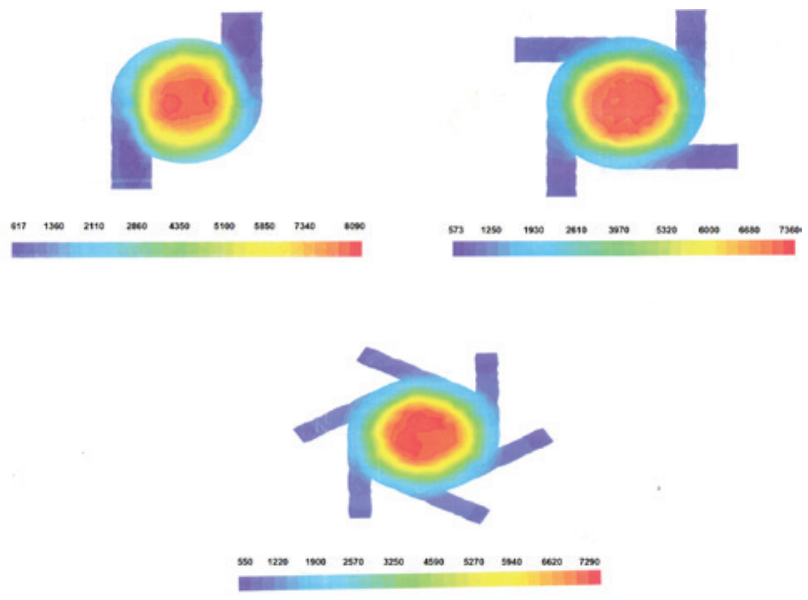

Figure 11. The turbulence kinetic energy for vortex tubes with two, four and six inlet nozzles

is the mixed flow inside the vortex tube. When the flow is laminar in the center of the vortex tube, the possibility of creating a mixed flow decreases; however, when the flow is turbulent in that section then a stronger mixed flow happens and the performance of the vortex tube decreases. The turbulence kinetic energy of vortex tubes with two, four and six inlet nozzles is shown in Figure 11.

The results show that the turbulence kinetic energy decreases with the increasing number of inlet nozzles because of the increasing tangential velocity component which can lead to a greater temperature separation and a higher performance of the vortex tube. To compare the temperature separation of different vortex tubes, a diagram of temperature distribution along the axial center line and radial direction in the middle of the vortex tubes is shown in Figure 12(a,b) respectively. It can be seen that when the number of inlet nozzles increases, the temperature separation will increase too.

The temperature separation for vortex tubes with different inlet nozzles is shown in Table 5.

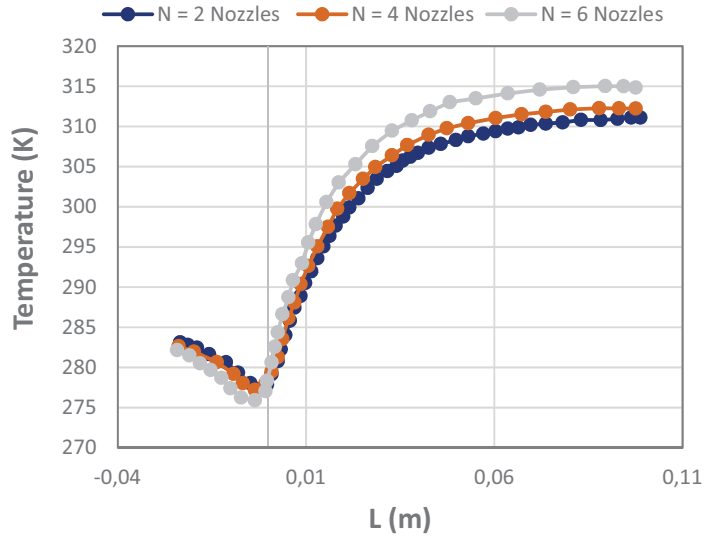

(a)

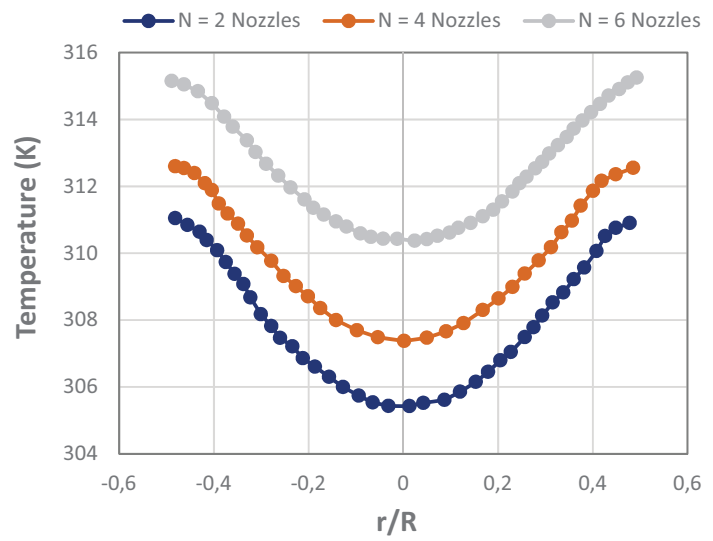

(b)

Figure 12. The diagram of (a) temperature distribution along the axial center line and (b) radial direction in the middle of the vortex tube 
Table 5. The temperature in different inlet nozzles

\begin{tabular}{|l|c|c|c|}
\hline $\begin{array}{c}\text { Number of } \\
\text { nozzles }\end{array}$ & $\begin{array}{c}\text { Cold } \\
\text { temperature } \\
(\mathrm{K})\end{array}$ & $\begin{array}{c}\text { Hot } \\
\text { temperature } \\
(\mathrm{K})\end{array}$ & $\begin{array}{c}\text { Temperature } \\
\text { difference } \\
(\mathrm{k})\end{array}$ \\
\hline Two & 286.2 & 309.85 & 23.65 \\
\hline Four & 285.76 & 310.986 & 25.226 \\
\hline Six & 285.2 & 313.416 & 28.216 \\
\hline
\end{tabular}

\subsection{Axial angle of inlet nozzle}

The effect of inlet nozzles with different axial angles on the performance of vortex tubes is investigated. Four different axial angles $(\theta)$ are studied such as: $\theta=0^{\circ}, 3^{\circ}, 5^{\circ}$ and $7^{\circ}$. A schematic of inlet nozzles with an axial angle is shown in Figure 13.

In Figure 14, a diagram of temperature versus the length of the vortex tube is plotted for analysing the effect of axial angle magnitude on the performance of the vortex tube.

As seen in Figure 14, with an increasing axial angle value, the temperature separation of the vortex tube will decrease till $\theta=5^{\circ}$ then it increases for $\theta=7^{\circ}$ and the performance of the vortex tube gets close to the vortex tube without an axial angle for the inlet nozzles. The turbulence kinetic energy and velocity magnitude are the key parameters for demonstrating the temperature separation phenomenon inside vortex tubes. In Figure 15, the turbulence kinetic energy contours for axial angles of $\theta=0^{\circ}, 3^{\circ}, 5^{\circ}$ and $7^{\circ}$ are shown and it is predicted that the temperature separation reach a maximum value when the turbulence kinetic energy has its minimum value at critical sections.
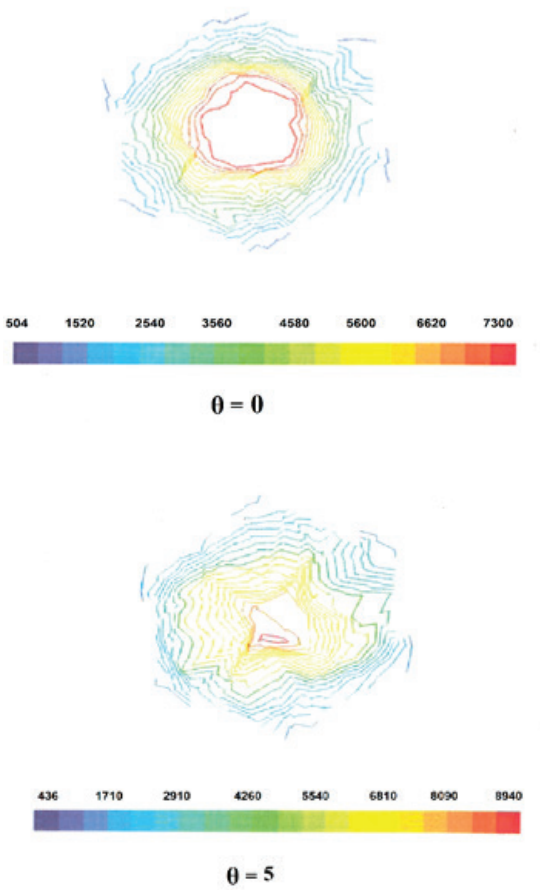

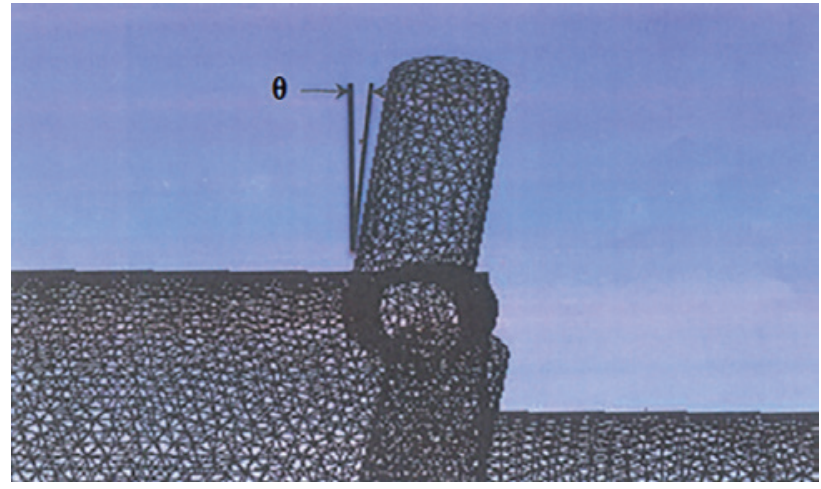

Figure 13. A schematic of the axial angle $(\theta)$ of an inlet nozzle

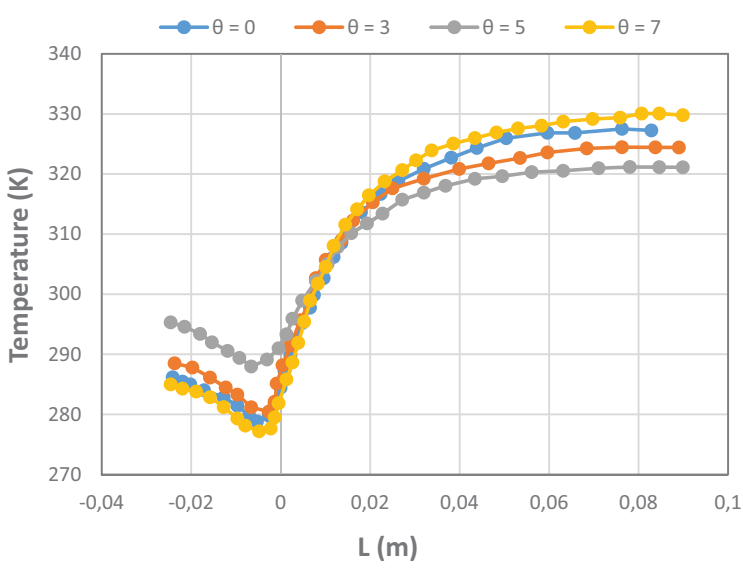

Figure 14. A diagram of temperature versus the length of the vortex tube for axial angle inlet nozzles of $\theta=0^{\circ}, 3^{\circ}, 5^{\circ}$ and $7^{\circ}$
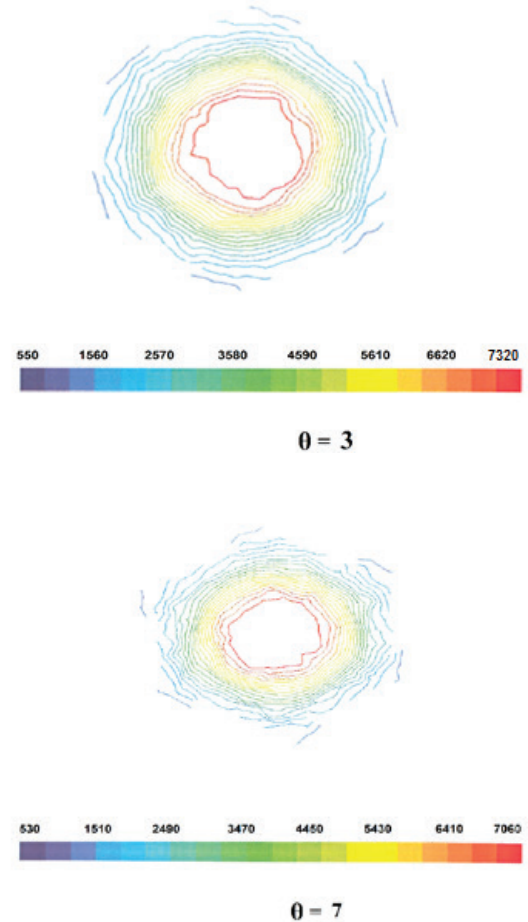

Figure 15. The turbulence kinetic energy contours for axial angle inlet nozzles of $\theta=0^{\circ}, 3^{\circ}, 5^{\circ}$ and $7^{\circ}$ 


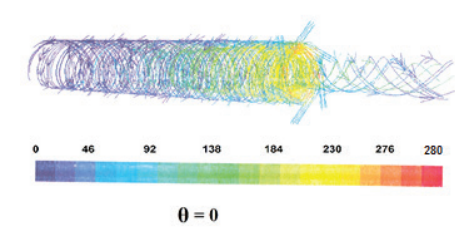

$\theta=0$

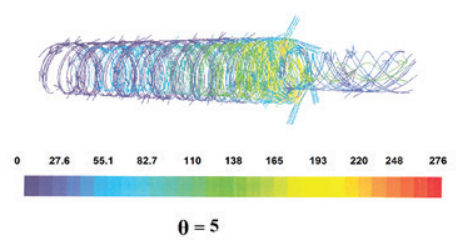

Figure 16. The contours of the velocity magnitude for axial angle inlet

nozzles of $\theta=0^{\circ}, 3^{\circ}, 5^{\circ}$ and $7^{\circ}$
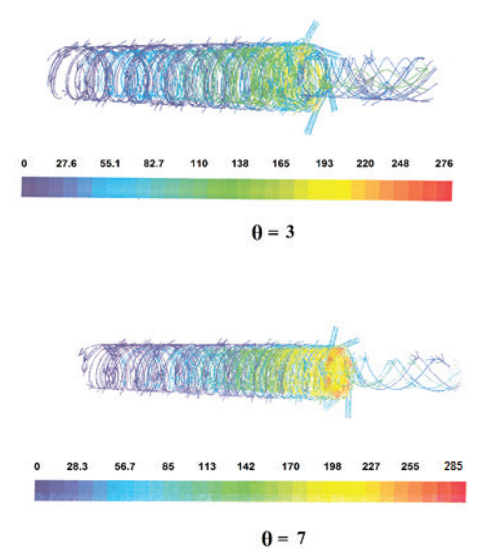

$\theta=7$
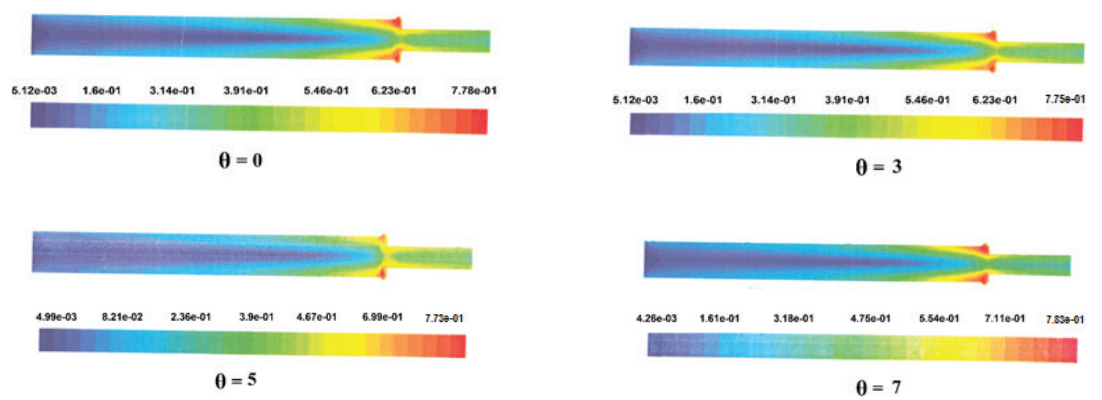

Figure 17. The contours of the Mach number for axial angle inlet nozzles of $\theta=0^{\circ}, 3^{\circ}, 5^{\circ}$ and $7^{\circ}$

As illustrated, for the axial angle of $\theta=5^{\circ}$, the value of turbulence kinetic energy appears to be at a maximum and it causes the lowest temperature separation and the minimum performance of the vortex tube. In addition, the velocity magnitude is another effective parameter of temperature separation thus the contours of the velocity magnitude are shown in Figure 16.

According to Figure 16, the highest and lowest velocity magnitude are obtained for those inlet nozzles which have an axial angle of $\theta=7^{\circ}$ and $5^{\circ}$ respectively. Generally, the effect of inlet nozzles with different axial angles on the performance of the vortex tube can be summarized as follows. First, inlet nozzles with an axial angle influence the Mach number and can omit some pulses and noisy voices. As seen in Figure 17, for inlet nozzles with axial angles, except for an axial angle of $\theta=7^{\circ}$, the Mach number is lower than that for the vortex tube without an axial angle. Consequently, noisy voices can be reduced by using inlet nozzles with axial angles instead of those vortex tubes without an axial angle. Second, using inlet nozzles with axial angles can decrease the velocity magnitude and temperature separation inside the vortex tube thus increasing the axial angle of inlet nozzles may decrease the performance of the vortex tube.

\section{Conclusions}

The temperature separation phenomenon inside the vortex tube is investigated with the help of Ansys Fluent 16.1 software. The geometry of the model was created in Gambit 2.4.6 software and then the mesh study of a twodimensional axisymmetric and a three-dimensional model was done. There are many parameters that can influence the performance of the vortex tube such as the number and axial angle of inlet nozzles. The major results of this research paper can be summarized as follows:

- by increasing the number of inlet nozzles, the surface area of each inlet nozzle decreases and this can increase the swirling velocity magnitude inside the vortex tube. Consequently, with increasing swirling velocity, a greater temperature separation will occur;

- according to the major application of the vortex tube in the temperature separation phenomenon, when the flow is turbulent inside the vortex tube, especially at a critical zone like the inlet, the performance of this device will decrease and vice versa;

- the vortex tube with axial angle inlet nozzles of $\theta=7^{\circ}$ has the lowest and highest turbulence kinetic energy and velocity magnitude, respectively, thus, the performance of this vortex tube is higher than that of the others; 
- the trend of increasing the axial angle magnitude of inlet nozzles with the temperature separation phenomenon is not a linear ascendant function. At the beginning, with increasing axial angle magnitude of the inlet nozzles, the temperature separation decreases, and afterwards it will have an increasing trend;

- when the axial angle magnitude of inlet nozzles is increased to $\theta=5^{\circ}$, the Mach number decreases and drops, afterwards it increases for an axial angle of $\theta=7^{\circ}$. When the inlet pressure is high, a strong shock or vibration may occur inside the vortex tube. To prevent the shocking phenomenon, inlet nozzles with axial angles can be used.

\section{Disclosure statement}

The Authors declare to have no competing financial, professional or personal interests from other parties.

\section{References}

Aljuwayhel, N., Nellis, G., \& Klein, S. (2005). Parametric and internal study of the vortex tube using a CFD model. International Journal of Refrigeration, 28(3), 442-450. https://doi.org/10.1016/j.ijrefrig.2004.04.004

Bazgir, A. (2017a, September). Ranque-Hilsch vortex tube: A numerical study. 2nd International Conference of Science and engineering In the Technology Era, Brussels, Belgium.

Bazgir, A. (2017b). Numerical investigation of flow pattern inside different counter-flow Ranque-Hilsch vortex tube refrigerators. 3rd International Conference on Innovation In science and Technology, Berlin, Germany.

Bazgir, A., Heydari, A. (2018). Energy conversion (efficiency) of straight counter-flow Ranque-Hilsch Vortex Tube (RHVT) by using optimized turbulence model. In Proceedings of ACN International Conference. Istanbul, Turkey.

Bazgir, A., Nabhani, N. (2018). Investigation of temperature separation inside various models of Ranque-Hilsch vortex tube: Convergent, straight, and divergent with the help of computational fluid dynamic approach. Journal of Thermal Science and Engineering Applications, 10(5), 051013.

Behera, U., Paul, P., Dinesh, K., \& Jacob, S. (2008). Numerical investigations on flow behaviour and energy separation in Ranque-Hilsch vortex tube. International Journal of Heat and Mass Transfer, 51(25), 6077-6089.

https://doi.org/10.1016/j.ijheatmasstransfer.2008.03.029

Behera, U., Paul, P., Kasthurirengan, S., Karunanithi, R., Ram, S., Dinesh, K., \& Jacob, S. (2005). CFD analysis and experimental investigations towards optimizing the parameters of Ranque-Hilsch vortex tube. International Journal of Heat and Mass Transfer, 48(10), 1961-1973.

https://doi.org/10.1016/j.ijheatmasstransfer.2004.12.046

Bovand, M., Valipour, M. S., Dincer, K., \& Tamayol, A. (2014). Numerical analysis of the curvature effects on Ranque-Hilsch vortex tube refrigerators. Applied Thermal Engineering, 65(1), 176-183. https://doi.org/10.1016/j.applthermaleng.2013.11.045

Bramo, R. A., \& Pourmahmoud, N. (2011). CFD simulation of length to diameter ratio effects on the energy separation in a vortex tube. Thermal Science, 15(3), 833-848. https://doi.org/10.2298/TSCI101004008B

Chang, K., Li, Q., Zhou, G., \& Li, Q. (2011). Experimental investigation of vortex tube refrigerator with a divergent hot tube. International Journal of Refrigeration, 34(1), 322-327.

https://doi.org/10.1016/j.ijrefrig.2010.09.001
Eiamsa-ard, S., \& Promvonge, P. (2007). Numerical investigation of the thermal separation in a Ranque-Hilsch vortex tube. International Journal of Heat and Mass Transfer, 50(5), 821832. https://doi.org/10.1016/j.ijheatmasstransfer.2006.08.018

Eiamsa-ard, S., \& Promvonge, P. (2008a). Numerical simulation of flow field and temperature separation in a vortex tube. International Communications in Heat and Mass Transfer, 35(8), 937947. https://doi.org/10.1016/j.icheatmasstransfer.2008.04.010

Eiamsa-ard, S., \& Promvonge, P. (2008b). Review of Ranque-Hilsch effects in vortex tubes. Renewable and Sustainable Energy Reviews, 12(7), 1822-1842. https://doi.org/10.1016/j.rser.2007.03.006

Eiamsa-ard, S., Wongcharee, K., \& Promvonge, P. (2010). Experimental investigation on energy separation in a counter-flow Ranque-Hilsch vortex tube: Effect of cooling a hot tube. International Communications in Heat and Mass Transfer, 37(2), 156162. https://doi.org/10.1016/j.icheatmasstransfer.2009.09.013

Farouk, T., \& Farouk, B. (2007). Large eddy simulations of the flow field and temperature separation in the Ranque-Hilsch vortex tube. International Journal of Heat and Mass Transfer, 50(23), 47244735. https://doi.org/10.1016/j.ijheatmasstransfer.2007.03.048

Fröhlingsdorf, W., \& Unger, H. (1999). Numerical investigations of the compressible flow and the energy separation in the Ranque-Hilsch vortex tube. International Journal of Heat and Mass Transfer, 42(3), 415-422. https://doi.org/10.1016/S0017-9310(98)00191-4

Hilsch, R. (1947). The use of the expansion of gasses in a centrifugal field as cooling process. Review of Scientific Instruments, 18(2), 108-113. https://doi.org/10.1063/1.1740893

Kazantseva, O., Piralishvili, S. A., \& Fuzeeva, A. (2005). Numerical simulation of swirling flows in vortex tubes. High Temperature, 43(4), 608-613. https://doi.org/10.1007/s10740-005-0102-8

Khodorkov, I., Poshernev, N., \& Zhidkov, M. (2003). The vortex tubea universal device for heating, cooling, cleaning, and drying gasses and separating gas mixtures. Chemical and Petroleum Engineering, 39(7-8), 409-415. https://doi.org/10.1023/A:1026336813155

Konzen, R. B. (1971). Gas-Vapor separation in a Ranque-Hilsch vortex tube. The American Industrial Hygiene Association Journal, 32(12), 820-825. https://doi.org/10.1080/0002889718506544

Liu, X., \& Liu, Z. (2014). Investigation of the energy separation effect and flow mechanism inside a vortex tube. Applied Thermal Engineering, 67(1), 494-506. https://doi.org/10.1016/j.applthermaleng.2014.03.071

Lucca-Negro, O., \& O'doherty, T. (2001). Vortex breakdown: a review. Progress in Energy and Combustion Science, 27(4), 431-481. https://doi.org/10.1016/S0360-1285(00)00022-8

Park, W.-G., \& Pouraria, H. (2014). Numerical investigation on cooling performance of Ranque-Hilsch vortex tube. Thermal Science, 18(4), 1173-1189.

Pouraria, H., \& Zangooee, M. (2012). Numerical investigation of vortex tube refrigerator with a divergent hot tube. Energy Procedia, 14, 1554-1559. https://doi.org/10.1016/j.egypro.2011.12.1132

Riu, K.-J., Kim, J.-s., \& Choi, I.-S. (2004). Experimental investigation on dust separation characteristics of a vortex tube. JSME International Journal Series B Fluids and Thermal Engineering, 47(1), 29-36. https://doi.org/10.1299/jsmeb.47.29

Saidi, M., \& Valipour, M. (2003). Experimental modeling of vortex tube refrigerator. Applied Thermal Engineering, 23(15), 1971-1980. https://doi.org/10.1016/S1359-4311(03)00146-7

Skye, H., Nellis, G., \& Klein, S. (2006). Comparison of CFD analysis to empirical data in a commercial vortex tube. International Journal of Refrigeration, 29(1), 71-80. https://doi.org/10.1016/j.ijrefrig.2005.05.004

Valipour, M. S., \& Niazi, N. (2011). Experimental modeling of a curved Ranque-Hilsch vortex tube refrigerator. International Journal of Refrigeration, 34(4), 1109-1116. https://doi.org/10.1016/j.ijrefrig.2011.02.013 
Van Patten, R., \& Gaudio, R. (1969). Vortex tube as a thermal protective device. Aerospace Medicine, 40(3), 289-292.

Williams, A. (1971). The cooling of methane with vortex tubes. Journal of Mechanical Engineering Science, 13(6), 369-375. https://doi.org/10.1243/JMES_JOUR_1971_013_057_02

Xue, Y., Arjomandi, M., \& Kelso, R. (2012). Experimental study of the flow structure in a counter flow Ranque-Hilsch vortex tube. International Journal of Heat and Mass Transfer, 55(21), 58535860. https://doi.org/10.1016/j.ijheatmasstransfer.2012.05.081

Xue, Y., Arjomandi, M., \& Kelso, R. (2013a). Experimental study of the thermal separation in a vortex tube. Experimental Thermal and Fluid Science, 46, 175-182.

https://doi.org/10.1016/j.expthermflusci.2012.12.009

Xue, Y., Arjomandi, M., \& Kelso, R. (2013b). The working principle of a vortex tube. International Journal of Refrigeration, 36(6), 1730-1740. https://doi.org/10.1016/j.ijrefrig.2013.04.016 